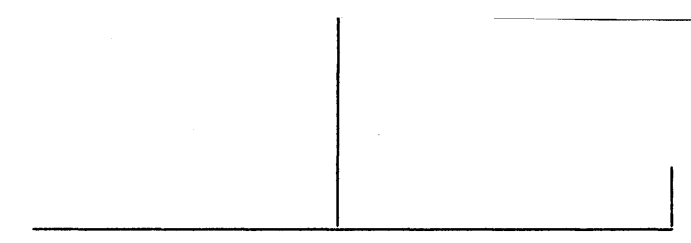

Rev. Latinoam. Psicopat. Fund., VII, 4, 77-87

\title{
Notas sobre o fantasma nas toxicomanias
}

\author{
Walter Firmo de Oliveira Cruz
}

O presente artigo foi apresentado na Jornada Clínica da Associação Psicanalítica de Porto Alegre - "A direção da cura nas toxicomanias: o sujeito em questão", em outubro de 2003. Através da discussão de um caso clínico, busca evidenciar a importância da relação existente entre a fantasmática do sujeito e a escolha do objeto nas toxicomanias. Aborda ainda a toxicomania como sintoma da contemporaneidade, bem como traços da estética que a compõe.

Palavras-chave: Toxicomania, psicanálise, fantasma, modernidade 


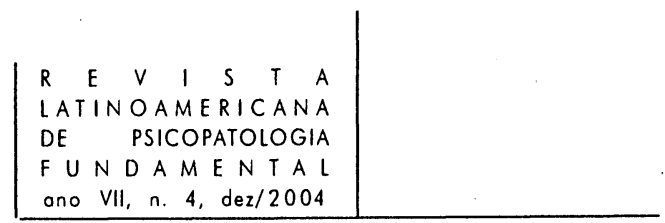

"Eu e minha antiga terapeuta chegamos à conclusão que eu deveria procurar uma ajuda especializada; então me indicaram teu nome", apresenta-se Cíntia em seu primeiro telefonema. Estávamos próximos do Natal e combinei de nos encontrarmos dois dias mais tarde. Olhar assustado, ao mesmo tempo procurando reconhecer o ambiente e buscando mostrar o quanto se sente desconfortável, diz que me procurou por ter estado em tratamento por mais de um ano com uma terapeuta que chamou de não-convencional. Segundo relata, o tratamento não alcançou o resultado esperado por ambas.

Cíntia me procura nomeando-se logo como "viciada". Conta que vem usando drogas desde a adolescência, mas que há aproximadamente 15 anos tem se dedicado a cheirar cocaína com certa regularidade, mesmo que se impondo algumas regras e limites.

Como que flagelada por essa ama exigente e nunca satisfeita, encontra-se, no momento em que me procura, completamente dividida entre a entrega ao estado de anestesia subjetiva, das noites de festa e da fala afirmativa e incessante, e o sentimento de arraso que se desdobra no decorrer dos dois ou três dias que se seguem ao consumo. A culpa, evidenciada pela vergonha que diz sentir, persegue-a implacavelmente: não passa impune ao se autodenominar uma viciada. Ao mesmo tempo em que imaginariamente encontra uma identidade, depara-se também com a culpa; uma falta, sua falta.

Aproximando-se dos quarenta anos, sem filhos, lhe convém levar a vida de forma independente. Segundo relata, o meio artístico em que vive e trabalha é o ideal, pois lhe permite autonomia, uma vez que divaga poder pegar uma pequena mala e começar tudo de novo, não importa onde. É, pois, a não convencionalidade da profissão que escolheu, a distância das regras formais do trabalho, aquilo que mais lhe parece atrativo no que faz.

Nossos encontros começam então a transcorrer, mas sempre com muita dúvida e crítica por parte de Cíntia. Questiona tudo: o fato de eu ser homem, o ambiente que considera essencialmente intimista do consultório (faz toda uma análise da "cenografia" da sala), a dificuldade que encontra em falar de si, os horários, pagamento etc.

Os braços cruzados, o olhar assustado e carregado de emoção quando se depara com o que tem para me contar, não lhe permitirão 


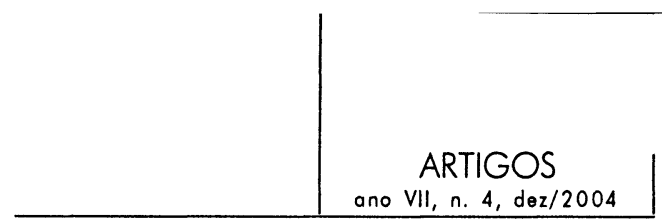

resistir mais que cinco ou seis encontros: alegará que dificuldades financeiras lhe impõe a necessidade de suspender temporariamente o trabalho que há pouco havíamos iniciado. Vale mencionar de forma particular o sofrimento que expressa quando começa a trazer fatos de seu passado. Sua história familiar é sempre apresentada com uma imensa e incompreensível dor: "minha mãe, minha família, isso sempre me dá vontade de chorar".

Passados então quase dois meses, faço contato convidando-a a retornar. O faz lançando mão de seu rol de explicações. Marca de Cíntia: é preciso sempre se explicar; cria situações em que se coloca constantemente em dívida.

Solta na vida, pertencendo a uma família que não compreende como a família que imagina, sentindo-se abandonada por uma mãe rival e afastada de um pai que por vezes não entende, à medida que Cíntia fala, vai compondo o cenário de sua infância e adolescência. As contradições em seu discurso vão surgindo constantemente: o modelo de família idealizada de sua infância é hoje por ela evitado. Forjar-se de modo a escapar de um certo ideal parece ter sido o caminho escolhido. Assim, imagina deixar para trás uma família na qual nunca encontrou seu lugar. As desavenças com a mãe foram decisivas em sua tentativa de afastamento. Lembranças dão conta de uma mãe sedutora, com quem durante um bom tempo rivalizou a atenção do pai.

Um acontecimento, aparentemente banal, foi marcante em sua infância fazendo com que Cíntia necessite voltar a falar diversas vezes nele: sua mãe resolve dar início a uma coleção de corujas que vão ocupando não apenas diversas prateleiras da sala, como durante algum tempo centralizará os assuntos na família. Em um desses momentos em que fala dessa coleção, perguntei-lhe se algum desses objetos colecionados lhe era especial: sim, responde; gostava muito de uma coruja que era transparente! O temor em tornar-se um objeto na estante é algo que mais tarde se repetirá em sua vida, especialmente no que tange aos seus relacionamentos amorosos. Não um objeto qualquer, mas um objeto transparente.

Fugindo de uma arriscada invisibilidade, Cíntia buscou ainda na adolescência ser autoral, espalhafatosa, falante e gesticuladora. Digo naquele tempo porque em nossos encontros raramente comparece vestida com outra (ausência de) cor senão o preto; sua fala é baixa e já não costuma gesticular. Constrói para si um mundo cuja infinidade de possibilidades deve estar garantida: as relações amorosas estabelecidas com seus parceiros estão sempre passíveis de serem rompidas; seu trabalho lhe permite imaginar poder viver em qualquer lugar; seus rendimentos são sempre incertos. E, quanto a maternagem... bom, isso foi algo que muito precocemente decidiu que não aconteceria em sua vida: tornou-se absolutamente inconcebível a idéia de ter alguém dependente dela.

Esforça-se em evitar escolhas. A possibilidade de manter uma certa conexão com o universal, com um todo se repete de diversas formas em seu discurso. 


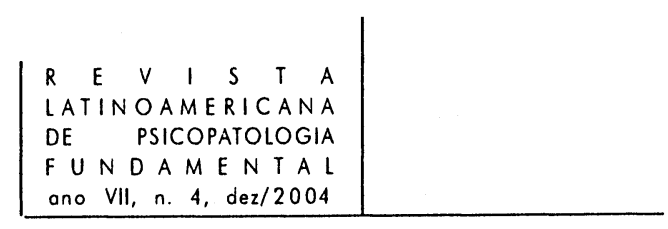

Aliás, é nessa mesma cadeia que fala da sua produção artística: uma possibilidade, um meio que tem de manter-se ligada ao todo da sociedade (Outro).

Bem, nesta fluidez em que Cíntia parece se deslocar (escorrer talvez seja mais preciso), há uma instância em sua vida que cumpre a função de lhe oferecer um ponto fixo, uma certeza: o cinza do dia seguinte. $O$ buraco que mergulha quando o efeito tóxico da cocaína passa. O break, utilizando suas palavras; a melancolia, utilizando as minhas. Assim, uma certeza não a abandona: após consumir cocaína, dois ou três dias de um mergulho atroz irá dominá-la.

Em uma vida que às vezes se assemelha a um barco cujos remos, pequenos demais, não lhe permitem senão manter-se em estado de flutuação ("luta muito para obter poucos resultados", dirá), no máximo algumas poucas amarras surgem de tempos em tempos (os limites que ela mesmo se impõe). Essas amarras, ou seja, um certo grau de dependência, consiste em um grande risco, uma vez que pode significar uma espera que se mostre infinita. A relação que mantém com seu companheiro atual, amalgamada pela cocaína que é de uso comum, é a mais estável que experimentou: "tem amor, sexo, companheirismo e cocaína". É bem verdade, em seu discurso vez ou outra irá inverter essa ordem.

No entanto, resta-lhe preservado um mundo de possibilidades que ao mesmo tempo ajudam a impedir que alguma escolha ocorra. A escolha põe em cena também o medo de fracassar ou de ter feito aquela que se revela posteriormente a errada. Assim, no plano das virtualidades, manter as possibilidades a protege de correr o risco de uma perda. Há, portanto, a paixão pela certeza, coisa que a cocaína, exatamente por seu efeito tóxico, sabe muito bem produzir. "A cocaína me deixa afirmativa... tu sabes das coisas. Fico mais autoral quando estou cheirada", me diz um certo dia.

Pois bem, certa vez, em uma sessão que não guardei registros senão em minha memória, Cíntia em seu tom melancólico, diz: "Sinto que perdi, mas não sei dizer o quê". Como quem diz de uma perda que se mantêm atual, Cíntia nos aponta na direção de um luto que não pôde ser realizado. Uma elaboração que "não pegou", uma repetição sem possibilidade de simbolização aí denunciada. Neste sentido, não encontra uma saída possível, uma vez que ficará sempre presa à repetição de um fracasso. É no real que ela ocorre, materializando-se no objeto droga. A repetição indica a insistência de algo que não encontra sua inscrição.

Sublinho agora aqui a busca de uma vida alternativa que se repete em sua fala. Desde o nosso primeiro contato em que anuncia o fracasso do tratamento "não convencional", passando pelas diferentes formas que pensa sua vida, a busca da produção de um "outro caminho" se revela particular em sua fantasmática. A idéia de ser alguém convencional, sem dúvida lhe aterrorizava. É tomado como algo que pode fazê-la desaparecer, "ser tragada". Sua existência de alguma forma encontra-se condicionada a uma constante reafirmação da possibilidade de escapar 


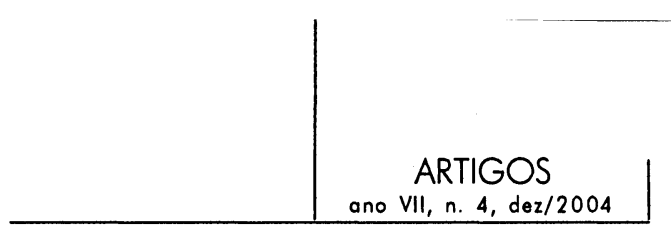

ocupar um lugar que lhe parece determinado de antemão. Isto poderá ser percebido também no tipo de transferência que estabelece comigo, uma vez que é muito rara a semana em que não procura remarcar o horário de sua consulta. Tenho, até então, aceitado ocupar esta posição.

Para Cíntia, em sua paixão pelo caminho "alternativo", é preciso se construir uma "mulher diferente". Diferente da mãe, poderíamos concluir. Sem dúvida este caminho passa também por fazer-se uma mulher não desejada.

Por analogia, a idéia que se estabelece é semelhante a alguém que se propõe a construir uma estrada, mas que, antes de mais nada, tem por objetivo não o chegar a algum lugar, mas opor-se a uma já existente e conhecida. Uma referência que nunca sai de cena, mesmo que seja para apontar para uma direção que não deve ser percorrida. A "alternativa" em momento algum permite esquecer que algo ocupa seu lugar, operando como uma instância que deva ser denegada. Assim como um espelho deformado, ao mirar o outro projeta o mesmo através de sua denegação.

Aliás, uma imagem que coloca bem a denegação na toxicomania é mostrada no filme Trainspotting, que, como vocês lembram (e quem não viu e se interessa pelas questões da toxicomania, eu recomendo), inicia perguntando sobre quem precisa de um rol de objetos e valores pequeno-burgueses, para concluir, em sua última cena, o grande interesse do protagonista pelos mesmos.

Para Cíntia, o mecanismo da denegação aos poucos tem mostrado suas limitações e o paradoxo começa a surgir diante de seus olhos: seus ideais de independência e liberdade - justamente o que organiza consideravelmente sua fantasmática - encontra um forte contraponto na relação de profunda dependência que estabelece com a droga. Banal, talvez, quando percebemos isto de fora da situação, mas com o poder de operar uma mudança em sua posição subjetiva, uma vez que muitas de suas certezas deixam de ter a eficácia de outrora.

\section{Fantasma}

A experiência da clínica torna bastante evidente a necessidade de haver uma articulação entre a droga de uso e a organização fantasmática de cada sujeito para que possamos falar em toxicomania. Hoje a presença das drogas em diversas esferas do laço social, transformou sua experimentação em algo nem tão acidental, e que interpela o percurso de muitos. Entretanto, como sabemos, estamos longe de achar (e mesmo constatar) que todos que passam por esta experiência tornamse toxicômanos.

Hoje temos drogas que cumprem as mais diversas funções na sociedade: que alimentam, aquecem e aliviam o desamparo das crianças na rua; drogas que 


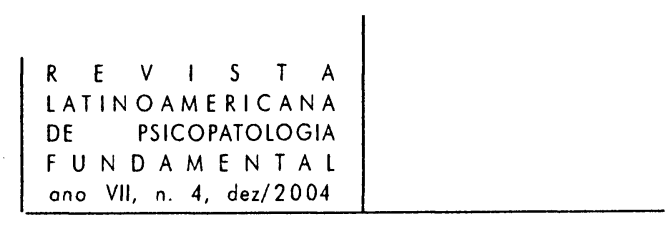

promovem uma certa inclusão em determinados laços sociais; embalam as festas da sociedade; promovem o relaxamento do final de um dia de trabalho, aliviam a solidão, enfim... Há, no mercado, tóxico - legal ou não - para aliviar quase todo tipo de tensão.

Neste sentido, como diz Charles Melmam, na atualidade torna-se toxicômano por acidente, uma vez que as drogas participam de diversas modalidades de troca na sociedade e proporcionam alguma forma de gozo. Se na atualidade o sujeito recebe a mensagem não do Outro, mas do consenso social, isto é, da opinião, sabemos que esta não é organizada senão pelo próprio gozo.

Observando aqui o percurso que Cíntia fez, podemos constatar que o tóxico escolhido, que o efeito tóxico produzido pela droga de sua escolha, é algo que vem justamente atender a um traço existente em sua fantasmática. A cocaína vem dar a sensação de um colorido, uma intensidade à palavra, conferindo-lhe o valor de verdade. Assim, atende a uma demanda de autoria, de tornar seu agente portador de uma palavra interessante e eficaz. Sem dúvida, isto colabora com o fato de a cocaína ser uma droga bastante consumida em determinados meios, em especial no meio artístico.

É preciso que exista uma consonância entre o fantasma de um sujeito e o efeito tóxico produzido pela droga (tanto como agente como pela conseqüência de sua ausência) para que se constitua uma toxicomania, independente aí de qual estrutura psíquica estejamos tratando.

Eu diria que para Cíntia o consumo da substância vale tanto pela sensação da palavra autoral produzida sob o efeito entorpecente, quanto pelo rebote do dia seguinte, que também se constitui em algo esperado por ela. É no momento em que acorda do sonho e depara-se frente ao espelho dos ideais, que se enxerga em dívida. A culpa que segue ao uso serve invariavelmente para interromper um caminho que parece estar indo bem: "Quando a coisa está indo legal eu cheiro; eu preciso disso; não ir assim, reto". Um pouco depois irá dizer: "Quando as coisas estão indo bem eu corto. Meu prêmio é me cortar".

Bem, é preciso destacar estas frases de Cíntia porque dizem de sua necessidade de produzir artificialmente um corte no circuito do gozo. Assim, o efeito da droga se positiva também pela operação que vai jogá-la no vazio. Entretanto, por este vazio não pegar, é preciso repeti-lo a cada vez. Poder simbolizar esta falta, transformando-a em uma instância psíquica, passível de ser feito um trabalho de luto, é o caminho por onde passa sua cura, não no sentido do consumo da droga, mas da travessia do fantasma. É importante frisar que quando tratamos de cura nas toxicomanias, não estamos necessariamente nos referindo a abstinência em relação à substância.

Fascinante a ponto de provocar os efeitos deslumbrantes de uma paixão (e daí a dificuldade que se tem de tomar em análise o toxicômano), a droga coloca 


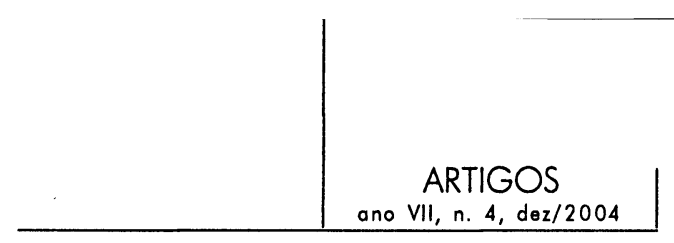

aqueles que ingressam em suas fileiras na condição de operários por um ideal. Mesmo que de uma forma pouco convencional, dá abrigo e protege, constituindose numa certeza - quando não numa causa (é freqüente vermos usuários ou exusuários engajarem-se em campanhas contra as drogas). As diversas formas de "cura" que se constituem numa conversão em que o sujeito passa a se ocupar da droga como militância, dão testemunho disso. Assim, freqüentemente incorporando-se aos diversos programas de tratamento e prevenção o sujeito contenta-se em manter uma paixão, digamos, platônica com a droga. É preciso encontrar o sujeito.

\section{Toxicomania e modernidade}

Dizer toxicomania na modernidade constitui, a meu ver, um verdadeiro pleonasmo. Seja como formação clínica ou mesmo sintoma social, são as condições específicas da modernidade, e principalmente para aqueles que partilham deste conceito, da pós-modernidade, que suportam através dos ideais eleitos, esta formação enquanto sintoma. Seja empresário de si mesmo, goze rápido, goze da posse do objeto. Afinal, seu valor depende disso.

A norma ditada pelo capitalismo é "consuma e faça-se ser consumido" (isto é o que faz com que você tenha valor, reconhecimento em seu meio) e não devemos jamais desprezar o aicance e a potência deste imperativo. Consumir e se fazer objeto de consumo, objetalizar o corpo, está no cerne das novas patologias de nossa cultura. O corpo vem ocupar um lugar importante neste novo cenário como aquilo que pode ser mostrado, que faz testemunho na sociedade do espetáculo.

O aprisionamento da tradição, dos lugares sociais fixos do sujeito prémoderno, foi substituído pela prisão do objeto. A proliferação infinita de saberes, marca da contemporaneidade, termina por nos lançar em um vazio de sentido. Como escreveu Alfredo Jerusalinsky (2002):

... a modernidade teve um irônico sucesso. Multiplicou os saberes, e também os deuses, até pulverizá-los. O drama da pós-modernidade é não ter a quem perguntar nem a quem implorar.

É por ali que vislumbramos o fracasso da modernidade do que se refere a seu primeiro princípio, o da autonomia do sujeito.

É ele o grande enganado desta história já que sua liberdade consiste apenas em poder escolher em qual discurso ele virá se representar para aceder a um lugar social, numa posição que autorize sua subjetividade. Sendo que qualquer um dos discursos que modalizam alguma forma de saber, atualmente estão tão fragmentados que é pouco ou nada o que lhe oferecem no que diz respeito à 


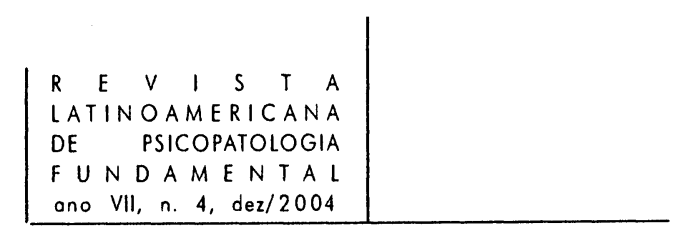

extensão da verdade. Pequenas verdades miseráveis que transformam o exercício de sua ilusória liberdade em poder escolher entre um nada e um quase nada. (p. 27)

Onde pensávamos encontrar a autonomia, vimo-nos alienados num saber infinito, cuja proliferação só faz ver sua insuficiência. Não há mais descanso pois não há método que não possa ser criado. O saber geral, absoluto, foi estilhaçado, fragmentando-se em uma multiplicidade de objetos. Nesta busca, desdobramo-nos em diversas formas, inclusive em mundos virtuais, cujas redes nos dão a sensação de acesso a esse inesgotável. Em nosso projeto - esse da modernidade - o que justamente se mostrou como insuficiente foram seus próprios pilares. Aqueles mesmos que sustentaram uma Revolução: uma liberdade que trouxe a incerteza e uma sociedade desigual e profundamente individualista.

O sujeito autônomo busca reparar a ausência de um saber (aquele que era transmitido pela tradição) com relações que, embora cada vez mais distanciadas, apresentam-se imediatas através da troca da informação, de uma conexão que produz a sensação de ultrapassamento das fragmentações a que estamos colocados. Esta é, sem dúvida, a crise gerada na modernidade. A liberdade de escolha é, também, a abertura para um mergulho na indecisão. A autonomia deste novo sujeito traz consigo a angústia da incerteza. A modernidade se propôs a ultrapassar a tradição através da informação, criando uma lacuna na história.

Assim, para Cíntia não é diferente, pois se trata também de romper com sua história; de colocá-la entre parênteses. Na lógica em que fica aprisionada, flutuando entre a denegação e o fato de estar em falta com o ideal, o que se produz a remete a um estado de melancolia. Ela encontra-se desta forma diante do mesmo impasse do sujeito da modernidade, uma vez que deve buscar realizar seu ideal de liberdade mas não pode prescindir do reconhecimento social. A denegação da história, operacionalizada pela droga, não a leva a outro lugar a não ser a prisão da repetição. Mais do que saber dizer, é preciso poder dizer.

\section{A estética da toxicomania}

Bem, trago aqui primeiramente algumas passagens do livro Bombons chineses cuja autora, Shen Wang (sob o pseudônimo Mian Mian, 2002) conta sua trajetória pelo submundo chinês nesta virada de século. Trata-se de um livro atualmente proibido pelo governo chinês, e que portanto circula clandestinamente naquele país. Aliás, de uma forma bastante apropriada e consoante com seu conteúdo, o próprio livro veio a constituir-se em um objeto de troca num comércio ilegal. 


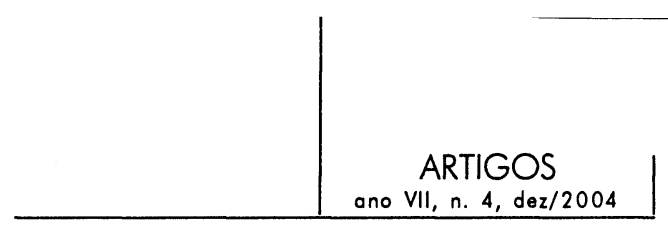

O livro conta a história de sua autora e suas incursões pelos guetos, bares, palcos e camas de duas ou três grandes cidades da China. Acaba retratando também, com grande sensibilidade, a estética que compõe este universo junkie. Vou deixar um pouco o próprio texto falar por suas palavras. Selecionei algumas passagens em que ela conta sua primeira experimentação de heroína, que ocorreu junto com seu namorado e que, em algum momento, se confunde com a paixão e a ausência desta:

Saining colocou um pouco de pó branco, meio amarelado, numa folha de papel alumínio para que eu pudesse inalar. Vomitei, sentia náuseas atrozes. Naquela noite não consegui parar de falar. Ele ficava bastante surpreso que a heroína me deixasse bastante falante. Deu-lhe até dores de cabeça. Aplicou-me mais uma dose para que eu voltasse ao normal. Quando me recuperei meu corpo estava todo moído, sentia um cheiro de produto usado para revelar fotografia. A heroína era glacial; não gostei muito, tinha a impressão de estar envolvida em algodão, não conseguia dormir, a impressão do algodão pouco a pouco se dissipou até finalmente desaparecer. Eu e meu corpo permanecemos com os nervos à flor da pele. (p. 64)

\section{Mais adiante:}

Às vezes eu o ajudava a resistir, outras vezes, ajudava-o a se drogar. Tornávamo-nos verdadeiros delinqüentes, correndo aqui e ali para descolar suas doses. Não agüentava mais, a droga nos tornava vulgares e baixos: era preciso que eu prestasse bastante atenção no dinheiro, por exemplo, e que eu tivesse sempre um pouco de heroína na bolsa, caso ele ficasse deprimido. Quando ele sentia falta, era como se eu não existisse, e não existia também quando ele partia para mais uma "viagem". Como era nula essa droga, que interesse havia? (...) Ele também achava tudo isso totalmente nulo, mas não era corajoso o suficiente para parar, hesitava o tempo todo entre se drogar ou parar. E isso, para ele, era mais nulo ainda. Não se picava, nem cheirava, contentava-se em inalar a fumaça de heroína que queimava. Entretanto, rapidamente as pessoas reconheciam, num piscar de olho, que se tratava de um drogado: ele tinha aquela aparência magra e pálida, aquele nervosismo estranho dos verdadeiros junkies. (...) nunca tivera objetos fixos na vida, agora ele tinha um, a droga, vivia uma competição com ela, era talvez perigoso, mas também divertido. (...) Quando o universo entra em coma, os amantes ficam infelizes. Eu e Saining, cada um perdido em suas brumas, podíamos confirmá-lo. (p. 70)

Bem, de certa forma podemos pensar que a estética toxicômana também mostra aquele que muitas vezes, em nossa sociedade, vai assumir o lugar do herói.

Mártir se for preciso, o toxicômano é capaz de lançar-se à morte quando se trata da realização de seu sonho. A imagem de sua degradação, de sua 
fragilidade, dos olhos profundos e sem vida, testemunham seu sofrimento e sua causa.

Sabemos que em algum momento a publicidade pôde captar isso e utilizar esta imagem como apelo comercial. Afinal, é preciso reconhecer um certo apego ao heroísmo, mas também à degradação que habita em cada um de nós.

Para encerrar esta parte, cito mais um trecho, desta vez do livro Diário de uma desintoxicação, de Jean Cocteau. Esta passagem foi extraída do livro de Jacques Hassoun (1997), A crueldade melancólica, que, devo confessar, em muito inspirou a escrita deste trabalho. Jean Cocteau:

Aproveitemos a insônia para tentar o impossível: descrever a necessidade. Byron dizia: "o amor não resiste à náusea". Como o amor, como a náusea, a necessidade penetra por tudo. A resistência é inútil. Primeiro um mal-estar. Depois as coisas se agravam. Imagine um silêncio que corresponda ao choro de milhares de crianças cujas amas de leite não chegam para dar-lhes o seio. A inquietação amorosa traduzida no sensível. Uma ausência que reina, um despotismo negativo (...) O corpo não esperava outra coisa senão novidades. Um cachimbo é suficiente. (p. 24)

\section{6}

\section{Finalizando}

Bem, propus aqui apenas um recorte de um caso clínico. O utilizei mais no sentido de provocar uma abertura no que concerne a nossa compreensão da questão das toxicomanias em nossa sociedade. Isto é, antes de tudo, da importante articulação que se estabelece entre a substância utilizada e a organização fantasmática de cada sujeito.

A meu ver, o valor destas considerações, articuladas com uma visão mais ampla do lugar que a droga ocupa em nossa sociedade, pode contribuir para o pensamento sobre estratégias de intervenção, especialmente no que diz respeito às políticas públicas de saúde. Estas, como sabemos, tendem a procurar saídas únicas que sejam comuns a todos a partir de suas sintomatologias.

Espero ter podido colaborar nessa reflexão.

\section{Referências}

Chagas, Silvia Spertino. A mulher toxicômana. Revista da Associação Psicanalítica de Porto Alegre, Porto Alegre, n. 24, p. 45-88, maio/2003.

Hassoun, Jacques. La cruauté mélancolique. Paris: Flammarion, 1997. 


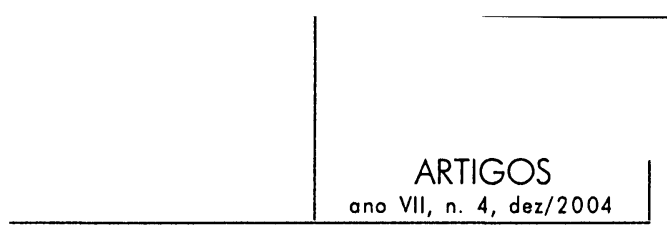

JERUSALINSKY, Alfredo. O mundo que inventamos - considerações sobre o discurso. Correio da APPOA, Porto Alegre, ano IX, n. 107, p. 24-28, 2002.

Melman, Charles. Novas formas clínicas no início do terceiro milênio. Porto Alegre: CMC Editora, 2003.

Mian-Mian. Bombons chineses. São Paulo: Geração Editorial, 2002.

Nogueira Filho, Durval Mazzei. Toxicomanias. São Paulo: Escuta, 1999.

\section{Resumos}

El presente artículo fue presentado en la Jornada Clínica de la Asociación Psicoanalítica de Porto Alegre - "La Dirección de la Cura en las Toxicomanías: el sujeto cuestionado", en octubre de 2003. A través de la discusión de un caso clínico, se busca evidenciar la importancia de la relación existente entre la fantasmática del sujeto y la elección del objeto en las toxicomanías como síntoma de la contemporaneidad asi como rasgos de la estética que la compone.

Palabras claves: Toxicomanía, psicoanálisis, fantasma, modernidad

Le présent article a été présenté lors de la Journée Clinique de l'Association Psychanalytique de Porto Alegre - "La direction de la cure dans les toxicomanies : le sujet en question", tenue en octobre 2003. Par la discussion d'un cas clinique, il vise à mettre en évidence l'importance du rapport existant entre la fantasmatique du sujet et le choix d'objet dans la toxicomanie. Il traite également de la toxicomanie comme symptôme de la contemporanéité et des traits esthétiques qui la composent.

Mots clés: Toxicomanie, psychanalyse, fantasme, modernité

This article was presented at a clinical meeting of the Porto Alegre Psychoanalytical Association entitled "The Path of Cure in Drug Addictions: the Subject at Issue," held in October, 2003. Starting with a discussion of a clinical case, this article treats the importance of the relationship that exists between the subject's fantasy and object choice in drug addiction. The article also discusses drug addiction as a symptom of contemporary society, and the aesthetic aspects that comprise it.

Key words: Drug addiction, psychoanalysis, fantasy, modernity

Versão inicial recebida em dezembro de 2003

Aprovado para publicação em setembro de 2004 